Article

\title{
Formation of Food Grade Microemulsion with Rice Glycosphingolipids to Enhance the Oral Absorption of Coenzyme Q10
}

\author{
Hiromasa Uchiyama, Jisoon Chae, Kazunori Kadota and Yuichi Tozuka * \\ Osaka University of Pharmaceutical Sciences, 4-20-1 Nasahara, Takatsuki, Osaka 569-1094, Japan; \\ uchiyama@gly.oups.ac.jp (H.U.); e13338@gap.oups.ac.jp (J.C.); kadota@gly.oups.ac.jp (K.K.) \\ * Correspondence: ytozuka@gly.oups.ac.jp; Tel.: +81-72-690-1218
}

Received: 20 September 2019; Accepted: 10 October 2019; Published: 15 October 2019

\begin{abstract}
The purpose of this study is to examine the possible use of rice glycosphingolipids (RGSLs) as an emulsifier to form food grade microemulsions (mean particle size, 10-20 nm) and improve the absorption of CoQ10 with a poor solubility property by prepared emulsion. Because RGSLs could act as an auxiliary emulsifying agent, its addition to the surfactant/oil mixture decreased the emulsion's particle size. This suggests that RGSLs exist between the water and oil phases to decrease oil droplet size via reduced interfacial tension. CoQ10-loaded microemulsion was also successfully prepared with RGSLs and powdered after freeze-drying with a cryoprotectant. CoQ10's solubility in freeze-dried particles was dramatically improved compared to that of CoQ10 powder. Moreover, oral absorption of CoQ10 was significantly enhanced when administered via CoQ10-loaded microemulsion. The area under the plasma concentration-time curve for the microemulsion improved up to seven-fold compared to CoQ10 powder. The use of RGSLs could, therefore, be an effective processing technique for improving CoQ10's solubility and absorption.
\end{abstract}

Keywords: rice glycosphingolipids; microemulsion; freeze dry; coenzyme Q10; oral absorption

\section{Introduction}

Coenzyme Q10 (CoQ10), existing in the inside of the inner mitochondrial membrane, functions as the production source of cellular energy and adenosine triphosphate. [1]. Many researchers have reported the beneficial effects of CoQ10 which include its antioxidant, anti-inflammatory, and anti-atherogenic activities [2-4]. In addition, CoQ10 intake has been reported to improve the symptoms of early Parkinson's disease and Huntington's disease [5]. One of the most prominent setbacks for the application of CoQ10 as a supplement is its poor dispersibility and solubility in polar solvents such as water and ethanol. Terao et al. reported that the aqueous solubility of CoQ10 is less than $0.1 \mu \mathrm{g} / \mathrm{mL}$ [6]. Hence, the absorption of CoQ10 from the gastrointestinal tract is limited by its poor solubility and large molecular weight $(863.34 \mathrm{~g} / \mathrm{moL})$ [7]. Oil-based formulations are available on the market as nutritional supplements to improve the absorption of CoQ10. In oil-based formulations, oil-in-water $(\mathrm{O} / \mathrm{W})$ emulsions encapsulated various poorly-soluble compounds, with a dispersed oil phase in aqueous solutions, are generally prepared by the apparatus, such as a high-pressure homogenizer and extruder, to supply energy that increases the water/oil interfacial area [8-10]. The particle size of emulsions prepared by these apparatuses shows the range from submicron to nano with a narrow particle distribution. [11,12]. Emulsions exhibiting a particle size less than $200 \mathrm{~nm}$ can be prepared by spontaneous emulsification without the use of an emulsifying apparatus [13,14]. Gulotta et al. reported that a nanoemulsion less than $100 \mathrm{~nm}$, including $\omega-3$ fatty acids, can be prepared using a spontaneous emulsification method [15]. On the other hand, it is important to select appropriate food 
additives to achieve spontaneous emulsification. Lipid mixtures with higher hydrophilic-lipophilic balance (HLB) surfactants, oils, and/or co-surfactants lead to the formation of nano-sized emulsion depending on their component ratios. Polysorbate 80 and d- $\alpha$-tocopherolpolyethylene glycol 1000 succinate, a non-ionic emulsifier, have been examined as high HLB surfactants to prepare nano-sized emulsions $[13,16]$. The emulsion prepared with these surfactants exhibited a particle size lower than $100 \mathrm{~nm}$ because of their high emulsifying potential. Lecithin, a mixture of glycerophospholipid, can also be used as an emulsifier $[17,18]$. Zhou et al. reported that an increase in the concentration of soybean lecithin, when used as an emulsifier, resulted in a decrease in particle size [19]. Natural biocompatible compounds such as lecithin are expected to function as an emulsifier.

Glycosphingolipids (GSLs) are essential components existing in mammalian cell membrane, particularly at the cell surface [20]. GSLs are amphipathic molecules that consist of a ceramide lipid moiety with an $\mathrm{N}$-acylated sphingosine group and glucose or galactose linked to the primary hydroxy group of the sphingosine moiety [21]. GSLs have been studied in various areas because of their superior effects, such as improvement of the immune system, barrier recovery, and skin moisturizing property [22,23]. However, it is difficult to process GSLs as a nutritional supplement drink and an oil-based formulation because of their low solubility in water or oil alone. On the other hand, GSLs may have potential as an emulsifier like lecithin because they possess an amphiphilic moiety and are constituents of the cell membrane. In this study, rice glycosphingolipids (RGSLs) were investigated as an additive to prepare a nano-sized $\mathrm{O} / \mathrm{W}$ emulsion containing CoQ10. The chemical structure of RGSLs is shown in Figure 1. The main composition of the fatty acid and sphingoid base in RGSLs was C20:0 and d18:2, respectively. Only a few studies have reported the application of RGSLs as an emulsifier.

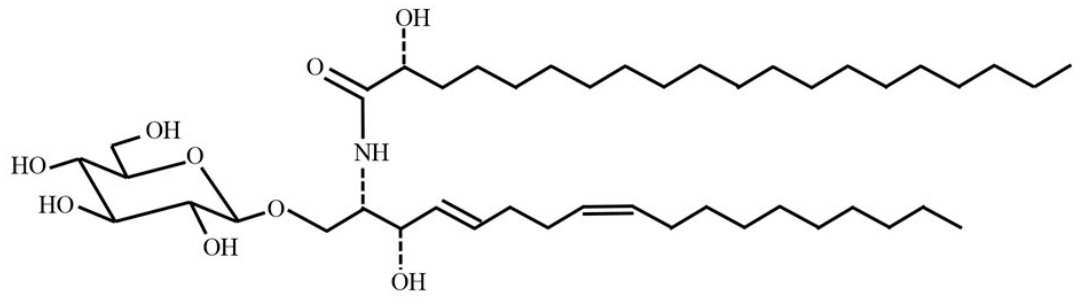

Figure 1. A chemical structure of rice glycosphingolipids. The main composition of the fatty acid and sphingoid base in glycosphingolipids (RGSLs) was C20:0 and d18:2, respectively.

The purpose of this study was to examine the possible use of RGSLs as an emulsifier and the effect of RGSLs addition to emulsion formation and enhance oral absorption of CoQ10 using prepared emulsion. Polysorbate 80 and Caprylic/capric triglyceride (TG) were used as a surfactant and oil, respectively. CoQ10 was used as a functional compound that displays poor water solubility. Because RGSLs do not dissolve in water and oil alone, CoQ10-loaded emulsion with RGSLs was prepared via hydration after evaporation. The powder containing CoQ10-loaded emulsion was prepared by the freeze-drying method with cryoprotectants. Furthermore, its re-dispersibility and solubility were evaluated using distilled water and biorelevant media. The pharmacokinetics of CoQ10 in a CoQ10-loaded emulsion were compared to those of untreated CoQ10 powder after oral administration to rats.

\section{Materials and Methods}

\subsection{Materials}

RGSLs was supplied by Okayasu Shoten Co., Ltd (Saitama, Japan). Polysorbate 80 and TG were supplied by Nikko Chemicals Co., Ltd (Tokyo, Japan). Coenzyme Q10 (CoQ10) was a gift from Nisshin Pharma Inc. (Tokyo, Japan) and Kyowa Hakko Bio Co., Ltd. (Tokyo, Japan). D-mannitol and sucrose were purchased from Wako Pure Chemical Industries (Osaka, Japan). All other chemicals and solvents 
were either of reagent grade or high-performance liquid chromatography (HPLC) grade and were used without further purification.

\subsection{Particle Size Measurement}

Particle sizes less than $1 \mu \mathrm{m}$ were measured with Nanotrac UPA by dynamic light scattering (UPA-UT151; MicrotracBEL, Osaka, Japan), while sizes more than $1 \mu \mathrm{m}$ were measured with Microtrac HRA by laser diffraction analysis (HRA-9320, MicrotracBEL). This measurement was performed in triplicate, and three times of data were averaged. A value of particle size was represented as volume-based particle size.

\subsection{Preparation of RGSLs, Polysorbate 80 , or RGSLs/Polysorbate 80 particles}

RGSLs (0.01, 0.1 and $1 \mathrm{mg})$, polysorbate $80(210 \mathrm{mg})$, or RGSLs $(50 \mathrm{mg})$ and Polysorbate 80 (210 mg) were dissolved in $10 \mathrm{~mL}$ of ethanol/acetone $(50 / 50, \mathrm{v} / \mathrm{v})$, and then processed by a rotary evaporator (R-3; Buchi, Tokyo, Japan) with a pressure of $102 \mathrm{mbar}$ in a $50{ }^{\circ} \mathrm{C}$ water bath. The mixture of ethanol/acetone was removed via adequate evaporation. Distilled water $(8 \mathrm{~mL})$ was added to the evaporated samples and sonicated for $10 \mathrm{~min}$. The particle size was determined by Nanotrac UPA or Microtrac HRA as described in Section 2.2.

\subsection{Preparation of Emulsion Without CoQ10}

RGSLs (0-90 mg), polysorbate $80(0-280 \mathrm{mg})$, and TG (70-140 mg) were dissolved in $10 \mathrm{~mL}$ of ethanol/acetone (50/50, v/v) and processed by a rotary evaporator (R-3; Buchi) with pressure of $102 \mathrm{mbar}$ in a $50{ }^{\circ} \mathrm{C}$ water bath. The mixture of ethanol/acetone was removed by adequate evaporation. Distilled water $(2-16 \mathrm{~mL}$ ) was added to the evaporated samples with a vortex and sonicated for $10 \mathrm{~min}$. Particle size was determined by a Nanotrac UPA or Microtrac HRA as described in Section 2.2.

\subsection{Preparation of CoQ10-Loaded Emulsion}

Polysorbate 80 (210 mg), RGSLs (50 mg), TG (100 mg), and CoQ10 (10-40 mg) were dissolved in $10 \mathrm{~mL}$ of ethanol/acetone (50/50, v/v) and processed by a rotary evaporator (R-3; Buchi) with a $102 \mathrm{mbar}$ pressure in a water bath at $50{ }^{\circ} \mathrm{C}$. The mixture of ethanol/acetone was removed via adequate evaporation. Distilled water $(8 \mathrm{~mL})$ was added to evaporated samples with vortex and then sonicated for $10 \mathrm{~min}$. Particle size was determined by a Nanotrac UPA as described in Section 2.2.

\subsection{Encapsulation Efficiency of CoQ10}

CoQ10-loaded emulsions were centrifuged at $6000 \mathrm{~g}$ for $10 \mathrm{~min}$ (1524, BM Equipment Co., Ltd., Tokyo Japan). The concentration of CoQ10 in the supernatant was determined using an HPLC (SPD-10A, Shimadzu Co., Ltd., Kyoto, Japan) with an ENDURO C18 (5 $\mu \mathrm{m}, 150 \mathrm{~mm} \times 4.6 \mathrm{~mm}$, SGE Analytical Science) column. The mobile phase consisted of ethanol and methanol (70:30, v/v). The flow rate was controlled at $1.0 \mathrm{~mL} / \mathrm{min}$ with a $30-\mu \mathrm{L}$ injection volume. CoQ10 was eluted at $40{ }^{\circ} \mathrm{C}$ and quantified at $275 \mathrm{~nm}$. The encapsulation efficiency of CoQ10 was determined by the following equation:

$$
\text { Encapsulation efficiency }(\%)=\frac{\text { CoQ10 concentration in supernatant }}{\text { Total CoQ10 concentration }} \times 100
$$

The CoQ10-loaded emulsion was kept in a water bath at $37^{\circ} \mathrm{C}$ for 4 weeks. Particle size and encapsulation efficiency of CoQ10 were evaluated at 1,2, and 4 weeks. The particle size of the emulsion was measured using Nanotrac UPA. The encapsulation efficiency of CoQ10 was determined by HPLC as described in Section 2.6. 


\subsection{Powder Preparation}

The powder containing CoQ10-loaded emulsion was prepared with mannitol or sucrose by the freeze-drying method. A double volume of mannitol or sucrose for components of CoQ10-loaded emulsion, except water, was added and then frozen at $-40^{\circ} \mathrm{C}$ for $30 \mathrm{~min}$ in a circulation bath (PFR-1000, Tokyo Rikakikai Co., Ltd., Tokyo, Japan). Lyophilization was performed at around $5 \mathrm{~Pa}$ for $24 \mathrm{~h}$ using a freeze-drier (FDU-830 freeze dryer, Tokyo Rikakikai Co., Ltd.).

\subsection{Morphology of Freeze-Dried Particles}

The morphology of samples was observed by scanning electron microscopy (SEM) (TM3030, HITACHI, Tokyo, Japan). Morphology observations were performed at an acceleration voltage of $15 \mathrm{kV}$. Samples were attached to carbon sticky tape mounted on SEM stubs. Prior to observation, samples were sputtered with a thin layer of platinum under vacuum.

\subsection{Re-Dispersibility of Freeze-Dried Particles}

The freeze-dried powder was re-dispersed in $5 \mathrm{~mL}$ of distilled water to achieve the same concentration as that before freeze-drying. The particle size of re-dispersed CoQ10-loaded microemulsion was measured by Nanotrac UPA or Microtrac HRA as described in 2.2.

\subsection{Solubility Test}

Solubility test was carried out in $20 \mathrm{~mL}$ of simulated gastric fluid or simulated intestinal fluid at $37^{\circ} \mathrm{C}$ and 100 strokes per minute using cool bath shaker (ML-10F, Taitec Corporation, Saitama, Japan). The simulated gastric fluid was a 0.1-M HCL solution while the simulated intestinal fluid was prepared as previously reported [24]. Briefly, a mixed solution was prepared by completely dissolving $6 \mathrm{mM}$ sodium taurocholate and $1.5 \mathrm{mM}$ lecithin (COATSOME ${ }^{\circledR} \mathrm{NC}-50$ ). Total of $7.8 \mathrm{~g}$ of $\mathrm{KH}_{2} \mathrm{PO}_{4}$ and $15.4 \mathrm{~g}$ of $\mathrm{KCl}$ were added to the mixed solution and the total volume was adjusted to $1 \mathrm{~L}$ with distilled water in a volumetric flask. The $\mathrm{pH}$ of the final solution was adjusted to 6.5 using $1 \mathrm{M} \mathrm{NaOH}$. Freeze-dried powders prepared with mannitol were added to $10 \mathrm{~mL}$ of dissolution media as a $5 \mathrm{mg}$ of CoQ10 content. One milliliter of samples was removed after $24 \mathrm{~h}$ and filtered through a $0.45 \mu \mathrm{m}$ PTFE-filter. The concentration of CoQ10 was determined by the HPLC method described in Section 2.6.

\subsection{Animal Study}

All animal experiments were approved by the Animal Research Committee of Osaka University of Pharmaceutical Sciences and were performed according to the Institutional Committees' regulations on animal experimentation. Male Sprague Dawley rats (9 weeks; 250-300 g; Japan SLC Inc., Shizuoka, Japan) were used. Six rats were used in each sample. The rats had fasted for $12 \mathrm{~h}$ before the start of the experiments. Rats were anesthetized using isoflurane. Untreated CoQ10 powder was dispersed in $0.5 \%$ carboxymethyl cellulose sodium salt. Untreated CoQ10 powder and CoQ10-loaded emulsion (equivalent to $30 \mathrm{mg} / \mathrm{kg}$ CoQ10 content) were orally administered to rats using an oral dosing syringe. Blood samples $(400 \mu \mathrm{L})$ were taken from the jugular vein at predetermined time intervals following administration. Plasma was obtained from blood samples by centrifugation for $10 \mathrm{~min}$ at $9730 \mathrm{~g}$. 2-propanol $(400 \mu \mathrm{L})$ was added to plasma $(100 \mu \mathrm{L})$ and the mixture was vortexed for 5 min prior to centrifugation at $9730 \times g$ for $10 \mathrm{~min}$ to separate the plasma proteins. The supernatant $(400 \mu \mathrm{L})$ was dried in a vacuum desiccator for one day and the residue was reconstituted with $100 \mu \mathrm{L}$ of methanol. The CoQ10 concentration in the supernatant was measured by an HPLC system (e2695 and 2489; Waters, Milford, USA) with a COSMOSIL 5C18-MS-II column $(5 \mu \mathrm{m}, 150 \mathrm{~mm} \times 4.6 \mathrm{~mm}$, Nacalai). The mobile phase was ethanol and methanol $(70: 30, \mathrm{v} / \mathrm{v})$, the flow rate was $0.7 \mathrm{~mL} / \mathrm{min}$, and the injection volume was $100 \mu \mathrm{L}$. CoQ10 was eluted at $40{ }^{\circ} \mathrm{C}$ and quantified at $275 \mathrm{~nm}$. The area under the plasma concentration-time curve (AUC) was determined by the trapezoidal method. 


\subsection{Statistical Analysis}

The results of the animal study are expressed as mean \pm S.E. of six experiments. Statistical significances between groups were analyzed using the Student $t$-test. Statistical significance was indicated as ${ }^{* *} p<0.01$.

\section{Results and Discussion}

\subsection{Evaluation of the Emulsion Without CoQ10}

\subsubsection{Evaluation of RGSLs, Polysorbate 80, and RGSLs/Polysorbate 80 Particles}

Particles of RGSLs $(0.01,0.1$, or $1 \mathrm{mg})$, Polysorbate 80 (210 mg), or Polysorbate 80 (210 mg) combined with RGSLs (50 mg) were prepared by adding $8 \mathrm{~mL}$ of distilled water after evaporation. Figure 2 shows the particle size distribution of RGSLs, Polysorbate 80, and Polysorbate 80/RGSLs particles.

(a)

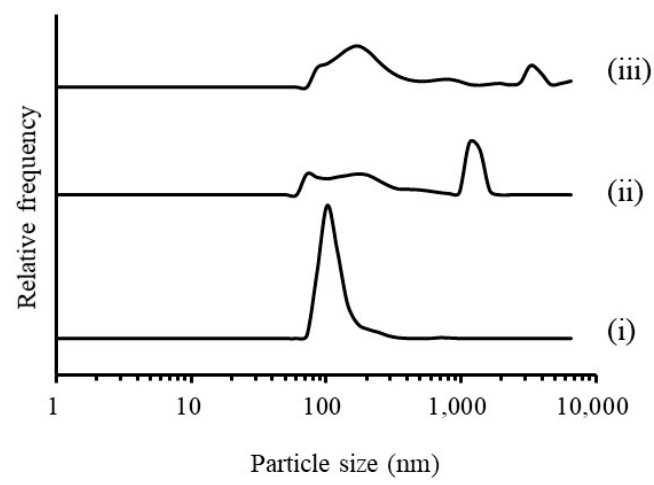

(b)

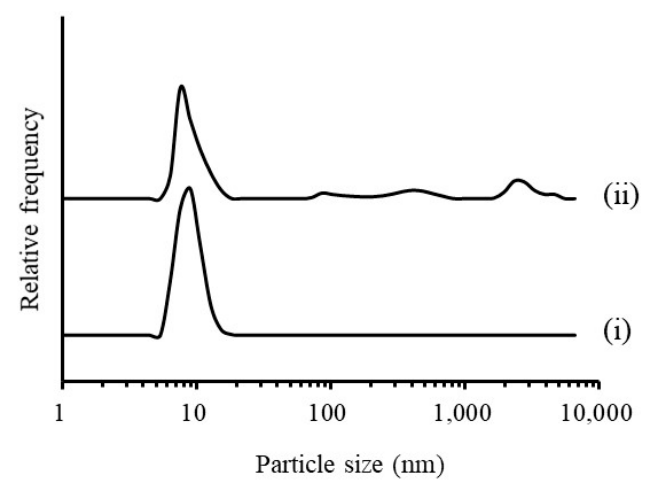

Figure 2. (a) Particle size distribution of rice glycosphingolipids (RGSLs) alone. ((i) $0.01 \mathrm{mg}$, (ii) $0.1 \mathrm{mg}$, and (iii) $1 \mathrm{mg}$ in $8 \mathrm{~mL}$ of distilled water). (b) Particle size distribution of (i) Polysorbate 80 alone or (ii) mixture of Polysorbate 80/RGSLs in $8 \mathrm{~mL}$ of distilled water.

As shown in Figure 2a, when $0.01 \mathrm{mg}$ of RGSLs was dispersed in $8 \mathrm{~mL}$ of distilled water after evaporation, the mean particle size of RGSLs was ca. $110.0 \mathrm{~nm}$. These particles were identified as liposomal particles as sphingolipids are components of the cell membrane in the lipid bilayer and can be used to form the liposomal structure with phospholipids [25]. Aggregated particles and their precipitation were observed in the aqueous solution with more than $0.1 \mathrm{mg}$ RGSLs. The particle prepared with polysorbate 80 and TG showed polydispersity as shown in Figure 2b. The peak of around $10 \mathrm{~nm}$ and the other peak were identified as polysorbate 80 micelles and RGSLs particles, respectively. The particles prepared with other ratios of polysorbate 80 and RGSLs also displayed polydispersity (data not shown). These results indicate that the bi-component of polysorbate 80 and RGSLs could not form mono-dispersed particles.

\subsubsection{Evaluation of the TG/RGSLs/Polysorbate 80 Emulsion}

It was difficult to disperse the high RGSLs concentration in water because of its poor solubility as shown in Figure 2a. RGSLs are amphiphilic molecules with their hydrophobic component consisting of a lipid bilayer in biological membranes. Therefore, RGSLs could form an emulsion because of their amphiphilicity. Polysorbate 80 and TG were used as emulsifier and oil, respectively. The mean particle size of the emulsion as a function of RGSL concentration is shown in Figure 3. 


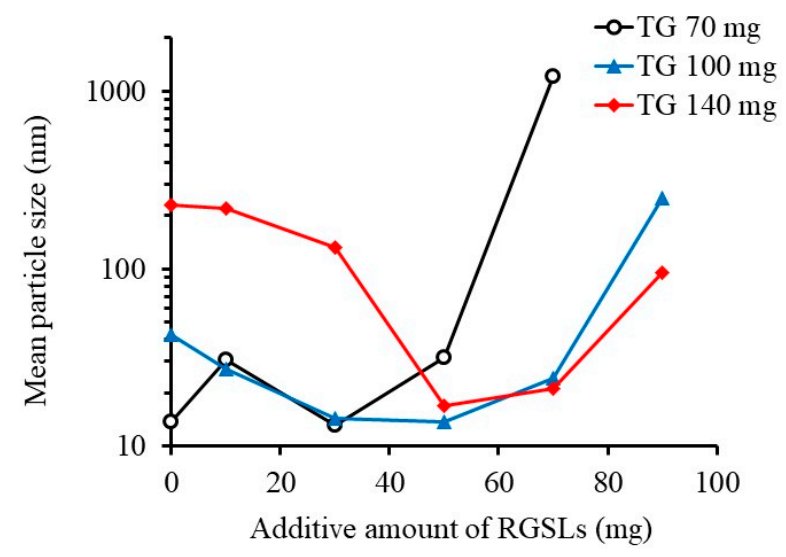

Figure 3. Effect of the additive amount of rice glycosphingolipids (RGSLs) in the formulation of polysorbate 80/caprylic/capric triglyceride (TG) on the particle size of the emulsion. The results are expressed as averages of three experiments. The emulsions were prepared with polysorbate $80(210 \mathrm{mg})$, TG (70, 100 or $140 \mathrm{mg})$ and RGSLs by adding $8 \mathrm{~mL}$ of distilled water after evaporation.

The emulsions were prepared with polysorbate 80 (210 mg), TG (70, 100, or $140 \mathrm{mg})$, and RGSLs by adding $8 \mathrm{~mL}$ of distilled water after evaporation. When the emulsions were prepared with the bi-components of polysorbate 80 and TG, the increase in TG amount in the emulsion enlarged the particle size. Mean particle sizes of the TG/polysorbate $80(70 / 210, \mathrm{w} / \mathrm{w})$, TG/polysorbate 80 $(100 / 210, \mathrm{w} / \mathrm{w})$, and TG/polysorbate $80(140 / 210, \mathrm{w} / \mathrm{w})$ emulsions were $13.7 \mathrm{~nm}, 42.7 \mathrm{~nm}$, and $228.9 \mathrm{~nm}$, respectively. The addition of RGSLs to the bi-component of TG/polysorbate $80(100 / 210, \mathrm{w} / \mathrm{w})$ and TG/polysorbate $80(140 / 210, \mathrm{w} / \mathrm{w})$ allowed preparation via self-emulsifying the microemulsion with a mean particle size of ca. $15 \mathrm{~nm}$ (Figure 4).
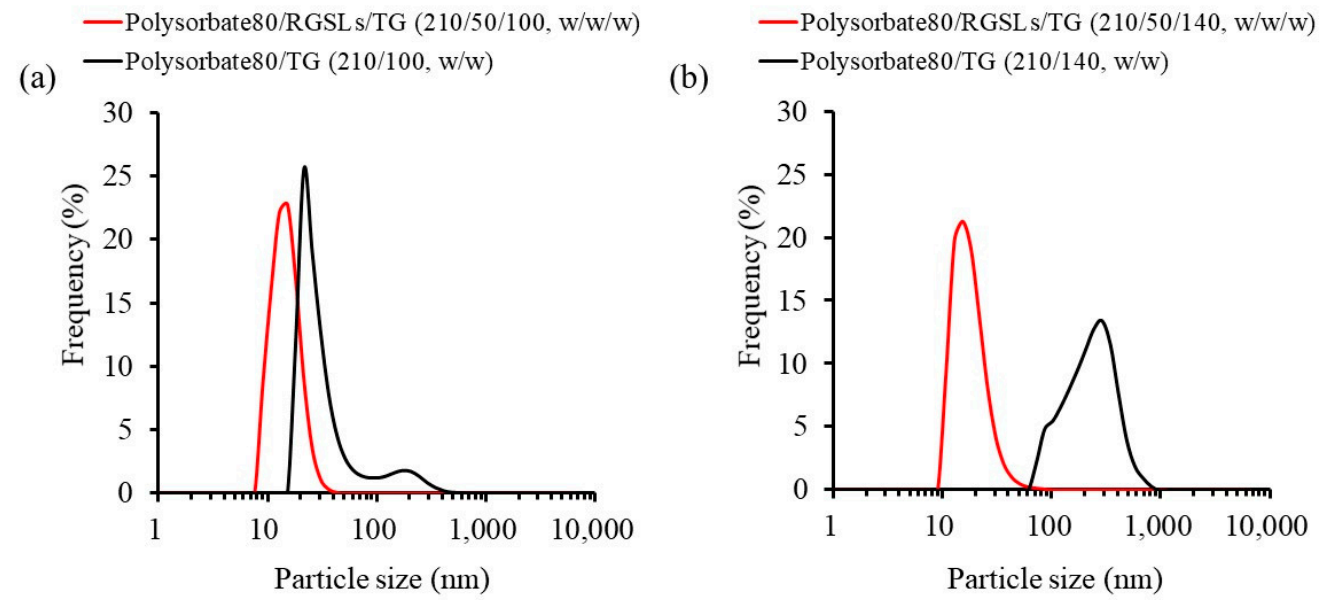

Figure 4. Particle size distribution of the emulsion with or without rice glycosphingolipids (RGSLs).

(a) The emulsions were prepared with polysorbate $80(210 \mathrm{mg}), \mathrm{TG}(100 \mathrm{mg})$, and RGSLs $(0 \mathrm{or} 50 \mathrm{mg})$.

(b) The emulsions were prepared with Polysorbate $80(210 \mathrm{mg})$, TG (140 mg) and RGSLs (0 or $50 \mathrm{mg})$.

Some reports have indicated that lecithin can form nano-sized lipid emulsion by acting as the emulsifier [26,27]. Hence, a lipid emulsion formed by lecithin has been applied to treat various diseases [27,28]. RGSLs can assist in the formation of a microemulsion by self-emulsification. This indicates that RGSLs can act as an auxiliary emulsifying agent in TG/polysorbate 80 formulation. Increasing the RGSLs content provided a new interfacial area associated with a decrease in interfacial tension between the water and oil phase, thereby leading to particle size reductions. In contrast, an excessive addition of RGSLs enlarged the particle size. The emulsion prepared with $70 \mathrm{mg}$ of TG increased the particle size because of the addition of fewer RGSLs compared to that with 100 and 
$140 \mathrm{mg}$ of TG. The increase in particle size was considered as a formation of the RGSLs liposomal particle alone after RGSL's orientation to the oil phase was saturated.

\subsubsection{Effect of Surfactant Content and Water Volume on Emulsion Formation}

A microemulsion can be prepared by adding RGSLs to a mixture of TG and polysorbate, and then, dispersing them in water. Oil volume was an important factor for directing RGSLs to the interface between water and oil. The optimized formulation was further investigated based on surfactant content and water volume. Figure 5 a shows the effect of polysorbate 80 content on the mean particle size of the emulsion.

(a)

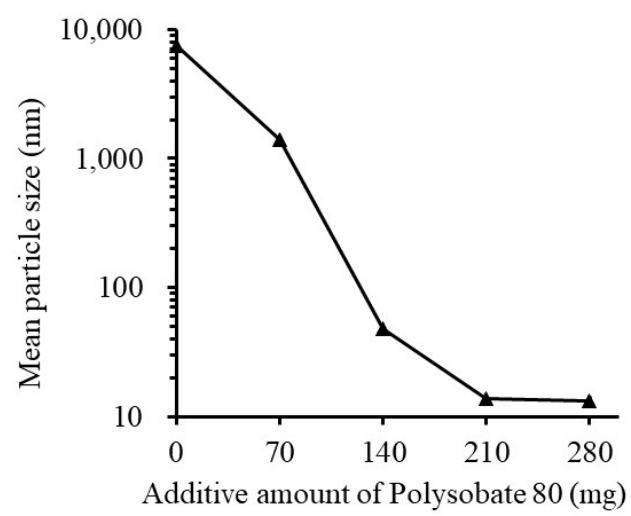

(b)

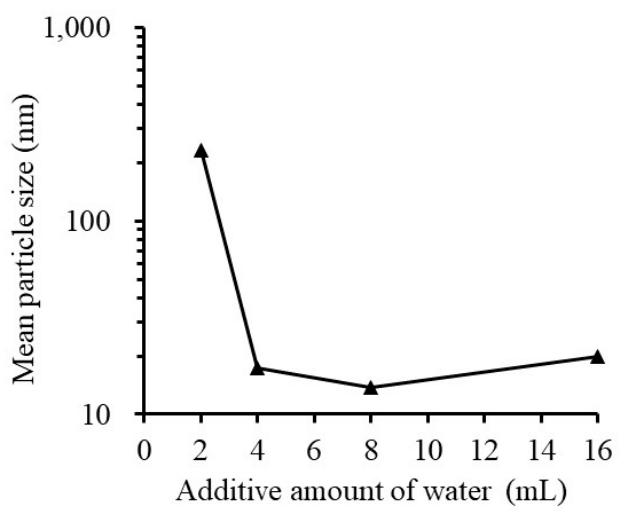

Figure 5. (a) Effect of the additive amount of polysorbate 80 on the particle size of the emulsion. The emulsions were prepared with polysorbate 80 , TG $(100 \mathrm{mg}$ ) and RGSLs (50 mg) by adding $8 \mathrm{~mL}$ of distilled water after evaporation. (b) Effect of the additive amount of water on the particle size of the emulsion. The results are expressed as an average of three experiments. The emulsions were prepared with polysorbate $80(210 \mathrm{mg})$, TG $(100 \mathrm{mg})$, and RGSLs $(50 \mathrm{mg})$ by adding distilled water after evaporation.

The emulsions were prepared with polysorbate 80 , TG (100 mg), and RGSLs (50 mg) with $8 \mathrm{~mL}$ of distilled water after evaporation because this formulation ratio showed the lowest particle size and the effect of addition of polysorbate 80 and water on particle size can be observed. The mean particle size of the emulsion decreased when polysorbate 80 content increased. The addition of more than $210 \mathrm{mg}$ of polysorbate 80 resulted in the formation of a microemulsion with a mean particle size of ca. $15 \mathrm{~nm}$. Figure $5 \mathrm{~b}$ shows the effect of water volume on the particle size of the emulsion. The emulsions were prepared with polysorbate $80(210 \mathrm{mg})$, TG $(100 \mathrm{mg})$, and RGSLs $(50 \mathrm{mg})$ and distilled water after evaporation. Increasing the water volume resulted in a decrease in the particle size of the emulsion. Microemulsion with a mean particle size of ca. $15 \mathrm{~nm}$ was prepared by adding more than $4 \mathrm{~mL}$ of water. Polysorbate $80(210 \mathrm{mg})$, TG (100 mg), RGSLs $(50 \mathrm{mg})$, and distilled water $(8 \mathrm{~mL})$ were selected as the formulation for the preparation of the CoQ10-loaded emulsion because emulsion prepared with this formulation showed the lowest particle size in the conditions investigated in this study.

\subsection{Evaluation of CoQ10-Loaded Microemulsion}

\subsubsection{Preparation of CoQ10-Loaded Emulsion}

Emulsions containing CoQ10 (10-40 mg) were prepared with polysorbate $80(210 \mathrm{mg})$, TG (100 mg), and RGSLs $(50 \mathrm{mg}$ ) with $8 \mathrm{~mL}$ of distilled water after evaporation. The particle size of the CoQ10 loaded-emulsion was then determined (Figure 6). 


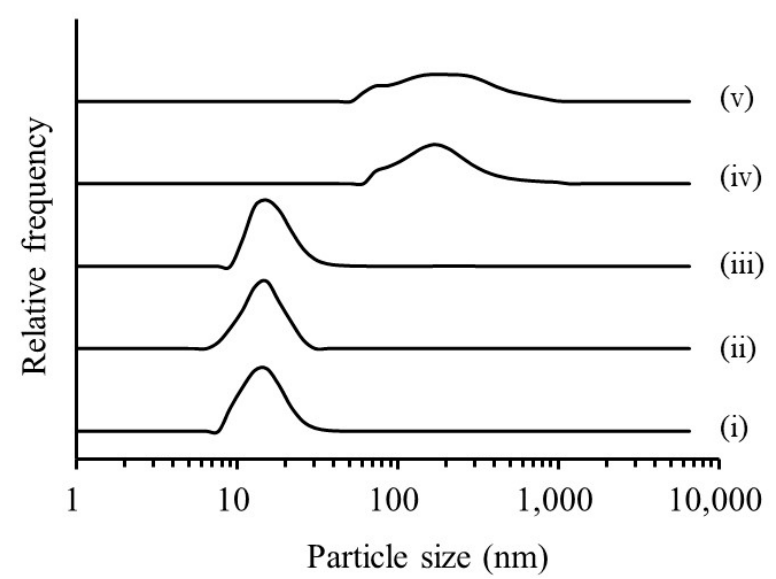

Figure 6. Effect of the additive amount of coenzyme Q10 (CoQ10) on particle size of the emulsion. (Additional CoQ10 content; (i) $0 \mathrm{mg}$, (ii) $10 \mathrm{mg}$, (iii) $20 \mathrm{mg}$, (iv) $30 \mathrm{mg}$ and (v) $40 \mathrm{mg}$ ).

When more than $20 \mathrm{mg}$ of CoQ10 was added to the emulsion, an increase in particle size was observed. This increased particle size was considered to reflect the formation of only the CoQ10 nanoparticle after being saturated in the oil phase or swelling of the emulsion by the encapsulation of excess CoQ10. Therefore, the emulsion containing $20 \mathrm{mg}$ of CoQ10 was prepared and evaluated as a change in mean particle size and encapsulation efficiency after storage for 4 weeks at $37^{\circ} \mathrm{C}$ (Table 1 ).

Table 1. Changes in particle size and encapsulation efficiency of coenzyme Q10 (CoQ10) loadedmicroemulsion after storage for 4 weeks at $37^{\circ} \mathrm{C}$. Each point represents the mean $\pm \mathrm{SD}(n=3)$.

\begin{tabular}{ccc}
\hline Storage Time (week) & Mean Particle Size (nm) & Encapsulation Efficiency (\%) \\
\hline 0 & $16.83 \pm 0.32$ & $100.34 \pm 0.92$ \\
1 & $17.37 \pm 0.90$ & $98.71 \pm 6.66$ \\
2 & $16.97 \pm 1.40$ & $102.3 \pm 4.86$ \\
4 & $17.17 \pm 1.81$ & $105.80 \pm 4.42$ \\
\hline
\end{tabular}

The mean particle size of the CoQ10-loaded microemulsion was $16.83 \pm 0.32 \mathrm{~nm}$. The encapsulation efficiency of CoQ10 in the emulsion was almost $100 \%$, indicating that CoQ10 was completely dissolved in the oil phase of the emulsion. When CoQ10-loaded microemulsion was stored for 4 weeks at $37^{\circ} \mathrm{C}$, the emulsion was stable without phase separation because a change in particle size and encapsulation efficiency did not occur compared to the product immediately after preparation. Normally, O/W emulsion is thermodynamically unstable because it is a colloidal dispersion of oil droplets in aqueous media. Long-term storage of $\mathrm{O} / \mathrm{W}$ emulsion caused a phase separation of oil droplets from the aqueous media, resulting in an increase in particle size and compound leakage from the oil phase. A microemulsion is generally defined as a thermodynamically stable isotropic liquid consisting of oil, surfactant, and water [29]. The free energy of the oil droplets in the microemulsion system was lower than that of the separate phases (oil and water), indicating that the microemulsion was thermodynamically stable. The microemulsion prepared with RGSLs showed a moderate storage stability based on particle size and encapsulation efficiency.

\subsubsection{Preparation of Freeze-Dried Powder Containing CoQ10-Loaded Microemulsion}

Because the freeze-dried powder could not be formed without a cryoprotectant, the CoQ10-loaded microemulsion was freeze-dried with a cryoprotectant of mannitol and sucrose. The morphology of freeze-dried particles was then evaluated. The morphology of the CoQ10 powder, RGSLs powder, and the freeze-dried particles was observed using SEM (Figure 7). 
(i)

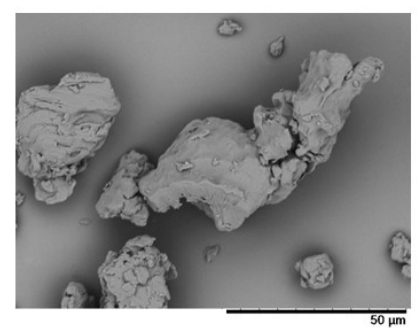

(iv)

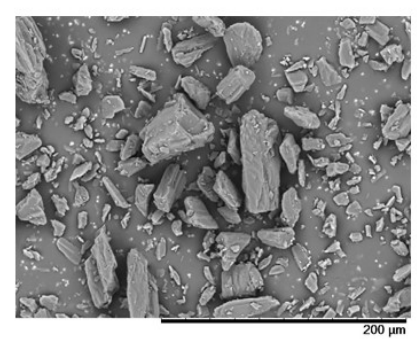

(ii)

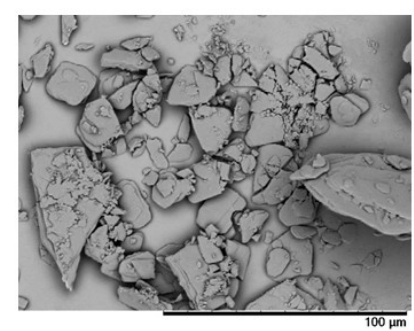

(v)

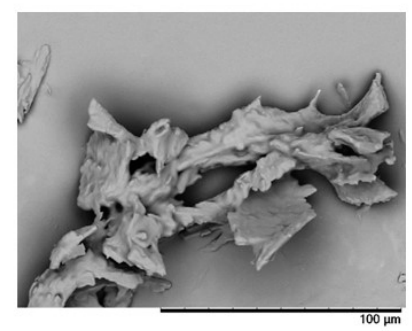

(iii)

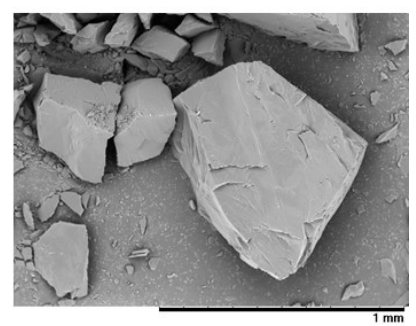

(vi)

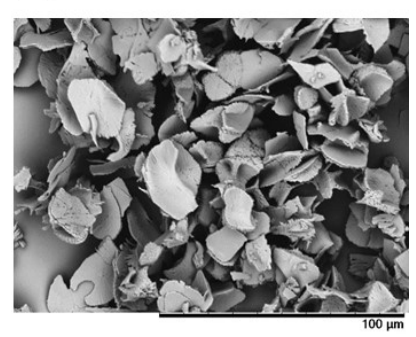

Figure 7. Scanning electron microscope (SEM) images of (i) coenzyme Q10 (CoQ10) powder, (ii) rice glycosphingolipid (RGSLs) powder, (iii) sucrose powder, (iv) mannitol powder, (v) freeze-dried particles of CoQ10-loaded microemulsion with sucrose, (vi) freeze-dried particles of CoQ10-loaded microemulsion with mannitol.

RGSLs and CoQ10 powders showed aggregates of particles that appeared formless and plate-like, respectively. The sucrose and mannitol powders displayed particles with a smooth surface and rough surface, respectively. Freeze-dried particles with sucrose showed an irregular particle with a rough surface. Aggregation of the fine particle was observed in the freeze-dried particles with mannitol. Particle size distribution after re-dispersal of the freeze-dried particles is shown in Figure 8.

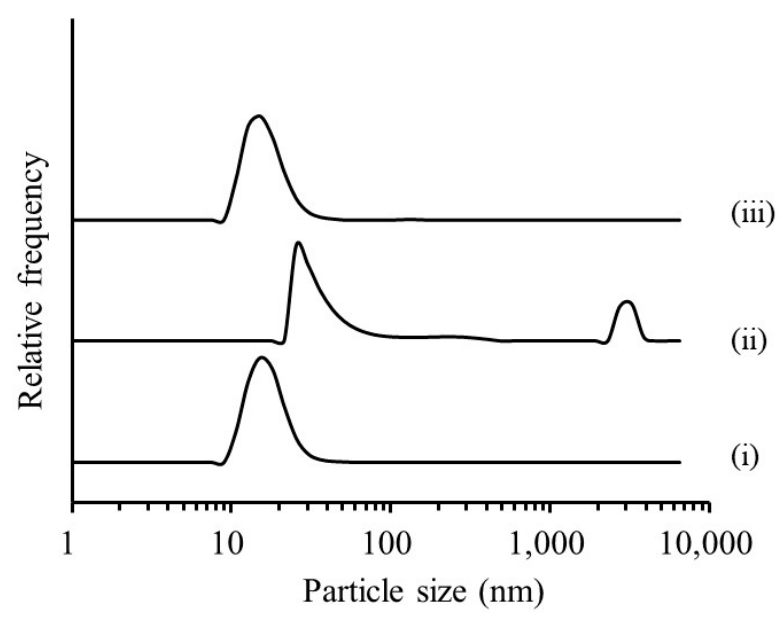

Figure 8. Particle size distribution of (i) emulsion before freeze drying, (ii) re-dispersed emulsion after freeze drying with sucrose, and (iii) re-dispersed emulsion after freeze drying with mannitol.

The particle size distribution after re-dispersal of the freeze-dried particles with mannitol was almost the same as that before freeze-drying. However, when the freeze-dried particles were prepared with sucrose, an increase in particle size was observed after the re-dispersal of the particles. Sugar alcohols such as sucrose and mannitol are widely used as a cryoprotectant to improve the re-dispersibility of emulsions in the freeze-drying process [30]. The presence of sugar alcohol decreases the freezing temperature of water, and then increases the amount of non-freezing water for oil droplet dispersal. For the concentrated sugar alcohol solution in the freeze-drying process, a close interaction does not 
exist with the oil droplets in non-freezing water, thereby inhibiting the merging of the oil droplets. In this study, the re-dispersibility of the emulsion after freeze-drying could, therefore, be enhanced by the addition of mannitol.

The solubility of CoQ10 from the freeze-dried particles of the CoQ10-loaded microemulsion with mannitol was compared to that of the CoQ10 powder in simulated gastrointestinal fluid (Table 2).

Table 2. Solubility of coenzyme Q10 (CoQ10) from the CoQ10 powder and freeze-dried particles of CoQ10-loaded microemulsion with mannitol in simulated gastrointestinal fluids.

\begin{tabular}{ccc}
\hline \multirow{2}{*}{ Test Solution } & \multicolumn{2}{c}{ Solubility of CoQ10 $(\mu \mathrm{g} / \mathrm{mL})$} \\
\cline { 2 - 3 } & CoQ10 Powder & CoQ10-Loaded Microemulsion \\
\hline Simulated gastric fluid & N.D. & $507.31 \pm 54.00$ \\
Simulated intestinal fluid & $0.44 \pm 0.03$ & $455.57 \pm 51.91$ \\
\hline
\end{tabular}

CoQ10-loaded microemulsion showed a dramatically higher solubility than the CoQ10 powder in simulated gastrointestinal fluids. CoQ10 is a highly lipophilic compound that exhibits an extremely low solubility in simulated gastrointestinal fluids as shown in Table 2. Nonetheless, the CoQ10-loaded microemulsion induced by RGSLs showed enhanced solubility in simulated gastrointestinal fluids, indicating that more than $500 \mu \mathrm{g} / \mathrm{mL} \mathrm{CoQ10}$ can be dissolved in emulsion with a formulation of RGSL (50 mg), polysorbate $80(210 \mathrm{mg})$, and TG $(100 \mathrm{mg})$. This result suggests that CoQ10 could be stably encapsulated in the oil phase even in the stomach and small intestine with a different $\mathrm{pH}$ value and salt concentration.

\subsubsection{Oral Absorption of CoQ10 from CoQ10-Loaded Microemulsion}

Figure 9 shows the plasma concentration-time profiles of CoQ10 in rats after being orally administered CoQ10 powder and CoQ10-loaded microemulsion.

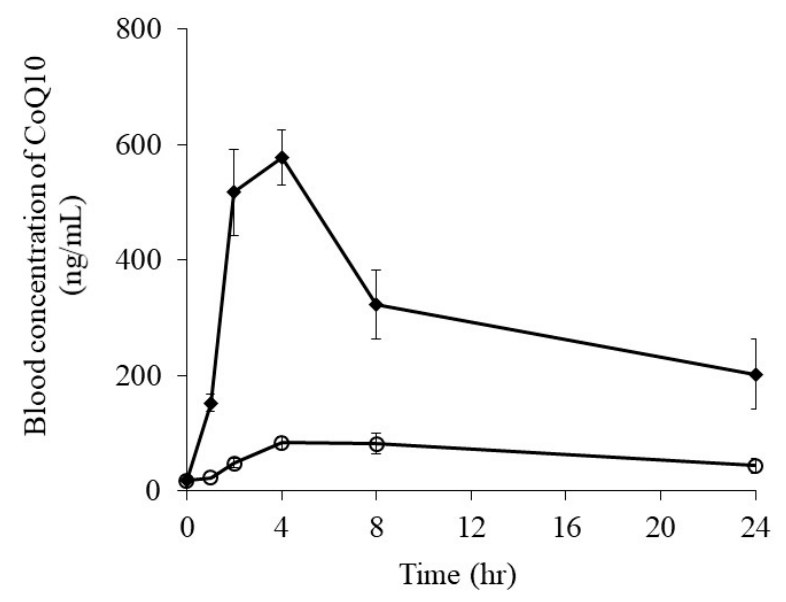

Figure 9. Plasma concentration-time profiles of coenzyme Q10 (CoQ10) in rats after oral administration of CoQ10 powder and CoQ10-loaded microemulsion $(\bigcirc$; CoQ10 powder, *; CoQ10-loaded microemulsion). Each point represents mean \pm S.E. $(n=6)$.

The oral absorption of CoQ10 was dramatically enhanced by encapsulating CoQ10 into the emulsion. Maximum drug concentrations (Cmax) of the CoQ10 powder and CoQ10-loaded microemulsion were $84.23 \pm 17.79$ and $578.09 \pm 47.47 \mathrm{ng} / \mathrm{mL}$, respectively (Table 3). For the CoQ10-loaded microemulsion, the increase in the AUC was 7.1-fold higher than that of the CoQ10 powder. Some reports have discussed the enhancement of CoQ10 oral absorption [31,32]. Encapsulating CoQ10 into solanesyl poly(ethylene glycol) succinate micelle and decreasing the particle size of its crystal improved its oral absorption. Although CoQ10 displays an extremely low solubility, these 
improved the oral absorptions caused by enhanced dissolution and solubility in the processing technologies. CoQ10-loaded microemulsion induced by RGSLs showed higher CoQ10 solubility in simulated gastrointestinal fluids. Enhanced solubility because of emulsification could contribute to the increased oral absorption of CoQ10. Its release from the microemulsion in the small intestine is also very important for its oral absorption, indicating that CoQ10 molecules must be released on the surface of the epithelial membrane before membrane permeation. Digestion by enzymes such as lipase is one of the processes for a compound's release from an emulsion [33]. An oral absorption study suggested that microemulsion formed using RGSLs could be digested in the gastrointestinal tract of rats and CoQ10 could be released, thereby contributing to its enhanced oral absorption.

Table 3. Pharmacokinetic parameters of coenzyme Q10 (CoQ10) after oral administration of CoQ10 powder and CoQ10-loaded microemulsion to rats ( ${ }^{* *} p<0.01$ compared to CoQ10 powder). Each point represents mean \pm S.E. $(n=6)$.

\begin{tabular}{ccc}
\hline & CoQ10 Powder & CoQ10 Loaded-Microemulsion \\
\hline Cmax $(\mathrm{ng} / \mathrm{mL})$ & $84.2 \pm 17.8$ & $578.1 \pm 47.5$ \\
$\operatorname{Tmax}(\mathrm{h})$ & 4.0 & 4.0 \\
AUC0-24 h $(\mathrm{ng} \cdot \mathrm{h} / \mathrm{mL})$ & $1050.9 \pm 202.6$ & $7503.6 \pm 1079.3^{* *}$ \\
\hline
\end{tabular}

\section{Conclusions}

RGSLs can assist in emulsifying the formulation consisting of polysorbate 80 and TG. RGSLs can exist on the interface of the water and oil phase and provide a new interfacial area by decreasing the interfacial tension between the oil and water phase. As a result, adding RGSLs to the polysorbate 80/TG formulation induced a reduction in the particle size of the emulsion. Prepared CoQ10-loaded microemulsion displayed high storage stability based on the particle size and encapsulation efficiency of CoQ10. Based on the high re-dispersibility of the CoQ10-loaded microemulsion powder, it could be prepared by freeze-drying with a cryoprotectant. Its freeze-dried particles showed enhanced CoQ10 solubility in simulated gastrointestinal fluids compared to the CoQ10 powder. Furthermore, oral administration of CoQ10-loaded microemulsion to rats significantly increased Cmax and AUC of CoQ10 compared to the values achieved with the CoQ10 powder. Altogether, the results demonstrate that food grade microemulsion induced by RGSLs will be an effective processing technique to improve the solubility and absorption of CoQ10.

Author Contributions: H.U. conceived the idea, designed the experiments, edited and prepared the draft; J.C. carried out the experiments and analyzed the data; K.K. gave the idea and provided refined the draft; and Y.T. prepared the final publication

Funding: This research was supported by grants from The Tojuro Iijima Foundation for Food Science and Technology.

Acknowledgments: We would like to thank Okayasu Shoten Co., Ltd. for their kind gift of rice glycosphingolipids; Nisshin Pharma Inc. and Kyowa Hakko Bio co., Ltd. for their kind gift of coenzyme Q10; and Nikko Chemicals Co., Ltd. for their kind gifts of Polysorbate 80 and Caprylic/capric triglyceride.

Conflicts of Interest: The authors declare no conflict of interest.

\section{References}

1. Christian, E.; Freye, K.; Strobel, H.-P. Coenzyme Q10 Supplements Which Increase ATP Synthesis within Mitochondria and Protect Against Toxic Sodium Azide. Acta Sci. Nutr. Health 2018, 2, 2-9.

2. Cadenas, E.; Davies, K.J.A.; Witting, P.K.; Pettersson, K.; Letters, J.; Stocker, R. Anti-atherogenic effect of coenzyme Q10 in apolipoprotein E gene knockout mice. Free Radic. Biol. Med. 2000, 29, 295-305.

3. Fuller, B.; Smith, D.; Howerton, A.; Kern, D. Anti-Inflammatory Effects of CoQ10 and Colorless Carotenoids. J. Cosmet. Dermatol. 2006, 5, 30-38. [CrossRef] [PubMed]

4. Crane, F.L. Biochemical Functions of Coenzyme Q10. J. Am. Coll. Nutr. 2001, 20, 591-598. [CrossRef] [PubMed] 
5. Beal, M.F.; Shults, C.W. Effects of Coenzyme Q 10 in Huntington's Disease and Early Parkinson's Disease. BioFactors 2003, 18, 153-161. [CrossRef] [PubMed]

6. Terao, K.; Nakata, D.; Fukumi, H.; Schmid, G.; Arima, H.; Hirayama, F.; Uekama, K. Enhancement of Oral Bioavailability of Coenzyme Q10by Complexation with $\gamma$-Cyclodextrin in Healthy Adults. Nutr. Res. 2006, 26, 503-508. [CrossRef]

7. Schulz, C.; Obermüller-Jevic, U.C.; Hasselwander, O.; Bernhardt, J.; Biesalski, H.K. Comparison of the Relative Bioavailability of Different Coenzyme Q10formulations with a Novel Solubilizate (SoluTM Q10). Int. J. Food Sci. Nutr. 2006, 57, 546-555. [CrossRef]

8. Bala, V.; Rao, S.; Prestidge, C.A. Facilitating Gastrointestinal Solubilisation and Enhanced Oral Absorption of SN38 Using a Molecularly Complexed Silica-Lipid Hybrid Delivery System. Eur. J. Pharm. Biopharm. 2016, 105, 32-39. [CrossRef]

9. Floury, J.; Desrumaux, A.; Lardières, J. Effect of High-Pressure Homogenization on Droplet Size Distributions and Rheological Properties of Model Oil-in-Water Emulsions. Innov. Food Sci. Emerg. Technol. 2000, 1, 127-134. [CrossRef]

10. Ogawa, S.; Decker, E.A.; McClements, D.J. Production and Characterization of O/W Emulsions Containing Cationic Droplets Stabilized by Lecithin-Chitosan Membranes. J. Agric. Food Chem. 2003, 51, 2806-2812. [CrossRef]

11. Joseph, S.; Bunjes, H. Preparation of Nanoemulsions and Solid Lipid Nanoparticles by Premix Membrane Emulsification. J. Pharm. Sci. 2012, 101, 2479-2489. [CrossRef] [PubMed]

12. Ogawa, S.; Decker, E.A.; McClements, D.J. Production and Characterization of O/W Emulsions Containing Droplets Stabilized by Lecithin-Chitosan-Pectin Multilayered Membranes. J. Agric. Food Chem. 2004, 52, 3595-3600. [CrossRef] [PubMed]

13. Davidov-Pardo, G.; McClements, D.J. Nutraceutical Delivery Systems: Resveratrol Encapsulation in Grape Seed Oil Nanoemulsions Formed by Spontaneous Emulsification. Food Chem. 2015, 167, 205-212. [CrossRef] [PubMed]

14. Guttoff, M.; Saberi, A.H.; Mcclements, D.J. Formation of Vitamin D Nanoemulsion-Based Delivery Systems by Spontaneous Emulsification: Factors Affecting Particle Size and Stability. Food Chem. 2015, 171, 117-122. [CrossRef]

15. Gulotta, A.; Saberi, A.H.; Nicoli, M.C.; McClements, D.J. Nanoemulsion-Based Delivery Systems for Polyunsaturated ( $\omega-3)$ Oils: Formation Using a Spontaneous Emulsification Method. J. Agric. Food Chem. 2014, 62, 1720-1725. [CrossRef]

16. Valicherla, G.R.; Dave, K.M.; Syed, A.A.; Riyazuddin, M.; Gupta, A.P.; Singh, A.; Wahajuddin; Mitra, K.; Datta, D.; Gayen, J.R. Formulation Optimization of Docetaxel Loaded Self-Emulsifying Drug Delivery System to Enhance Bioavailability and Anti-Tumor Activity. Sci. Rep. 2016, 6, 26895. [CrossRef]

17. Kelmann, R.G.; Kuminek, G.; Teixeira, H.F.; Koester, L.S. Carbamazepine Parenteral Nanoemulsions Prepared by Spontaneous Emulsification Process. Int. J. Pharm. 2007, 342, 231-239. [CrossRef]

18. Sjöström, B.; Westesen, K.; Bergenståhl, B. Preparation of submicron drug particles in lecithin-stabilized o/w emulsions. II. Characterization of cholesteryl acetate particles. Int. J. Pharm. 1992, 94, 89-101. [CrossRef]

19. Zhou, H.; Yue, Y.; Liu, G.; Li, Y.; Zhang, J.; Gong, Q.; Yan, Z.; Duan, M. Preparation and Characterization of a Lecithin Nanoemulsion as a Topical Delivery System. Nanoscale Res. Lett. 2010, 5, 224-230. [CrossRef]

20. Wennekes, T.; van den Berg, R.J.; Boot, R.G.; van der Marel, G.A.; Overkleeft, H.S.; Aerts, J.M. Glycosphingolipids-Nature, Function, and Pharmacological Modulation. Angew. Chem. Int. Ed. 2009, 48, 8848-8869. [CrossRef]

21. Yamashita, T.; Wada, R.; Sasaki, T.; Deng, C.; Bierfreund, U.; Sandhoff, K.; Proia, R. A vital role for glycosphingolipid synthesis during development and differentiaion. Seikagaku 2000, 72, 1420-1425. [PubMed]

22. Inoue, J.; Ideue, R.; Takahashi, D.; Kubota, M.; Kumazawa, Y. Liposomal Glycosphingolipids Activate Natural Killer T Cell-Mediated Immune Responses through the Endosomal Pathway. J. Control Release 2009, 133, 18-23. [CrossRef] [PubMed]

23. Mao-qiang, M.A.N.; Feingold, K.R.; Wang, F.; Thornfeldt, C.R.; Elias, P.M. A Natural Lipid Mixture Improves Barrier Function and Hydration in Human and Murine Skin. J. Soc. Cosmet. Chem. 1996, 47, 157-166.

24. Galia, E.; Nicolaides, J.E.; Horter, D.; Lobenberg, R.; Reppas, C.; Dressman, J.B. Evaluation of Various Dissolution Media for Predicting in Vivo Performance of Class I and II Drugs. Pharm. Res. 1998, 15, 698-705. [CrossRef] [PubMed] 
25. Kaneko, K.; McDowell, A.; Ishii, Y.; Hook, S. Liposomal $\alpha$-galactosylceramide is taken up by gut-associated lymphoid tissue and stimulates local and systemic immune responses. J. Pharm. Pharmacol. 2017, 69, 1724-1735. [CrossRef] [PubMed]

26. Donsì, F.; Annunziata, M.; Vincensi, M.; Ferrari, G. Design of nanoemulsion-based delivery systems of natural antimicrobials: Effect of the emulsifier. J. Biotechnol. 2012, 159, 342-350. [CrossRef] [PubMed]

27. Seki, J.; Sonoke, S.; Saheki, A.; Fukui, H.; Sasaki, H.; Mayumi, T. A nanometer lipid emulsion, lipid nano-sphere $\left(\mathrm{LNS}^{\circledR}\right)$, as a parenteral drug carrier for passive drug targeting. Int. J. Pharm. 2004, 273, 75-83. [CrossRef]

28. Trang, P.; Wiggins, J.F.; Daige, C.L.; Cho, C.; Omotola, M.; Brown, D.; Weidhaas, J.B.; Bader, A.G.; Slack, F.J. Systemic delivery of tumor suppressor microRNA mimics using a neutral lipid emulsion inhibits lung tumors in mice. Mol. Ther. 2011, 19, 1116-1122. [CrossRef]

29. McClements, D.J. Nanoemulsions versus microemulsions: Terminology, differences, and similarities. Soft Matter 2012, 8, 1719-1729. [CrossRef]

30. Li, F.; Wang, T.; He, H.B.; Tang, X. The properties of bufadienolides-loaded nano-emulsion and submicro-emulsion during lyophilization. Int. J. Pharm. 2008, 349, 291-299. [CrossRef]

31. Qin, B.; Liu, L.; Pan, Y.; Zhu, Y.; Wu, X.; Song, S.; Han, G. PEGylated Solanesol for Oral Delivery of Coenzyme Q 10. J. Agric. Food Chem. 2017, 65, 3360-3367. [CrossRef] [PubMed]

32. Swarnakar, N.K.; Thanki, K.; Jain, S. Lyotropic liquid crystalline nanoparticles of CoQ10: Implication of lipase digestibility on oral bioavailability, in vivo antioxidant activity, and in vitro-In vivo relationships. Mol. Pharm. 2014, 11, 1435-1449. [CrossRef] [PubMed]

33. Li, Y.; Hu, M.; McClements, D.J. Factors affecting lipase digestibility of emulsified lipids using an in vitro digestion model: Proposal for a standardised pH-stat method. Food Chem. 2011, 126, 498-505. [CrossRef]

(C) 2019 by the authors. Licensee MDPI, Basel, Switzerland. This article is an open access article distributed under the terms and conditions of the Creative Commons Attribution (CC BY) license (http://creativecommons.org/licenses/by/4.0/). 